\title{
Public Sector Equality Duty: Enforcing equality rights through second-generation regulation
}

\begin{abstract}
:
This article reviews the effectiveness of the Public Sector Equality Duty (PSED), based on insights from debates within equality law and theories of regulation. Drawing on examples of its practical implementation, the strengths and weaknesses of the 'reflexive turn' in equality law are assessed. Whilst recognising the concerns raised regarding second-generation regulation, such as its inability to address structural power relations, the article proposes that this form of regulation has some merit when applied to equality law. First, the participatory processes that it produces can in themselves be viewed as equality outcomes, particularly when equality is understood to encompass the participation and inclusion of vulnerable groups. Second, this form of regulation can introduce change within organisations, proving reasonably resilient once embedded in standards of good management practice. The paper does not suggest that the processes of the PSED cannot be improved, and instead proposes a number of ways in which second-generation regulation can be made more effective. However, it argues that examples of the implementation of the PSED show how reflexive regulation can provide more effective and resilient means to support the realisation of equality and social justice than at first appears.
\end{abstract}

Authors:

Simonetta Manfredi, Lucy Vickers, Kate Clayton-Hathway*

*Oxford Brookes University,

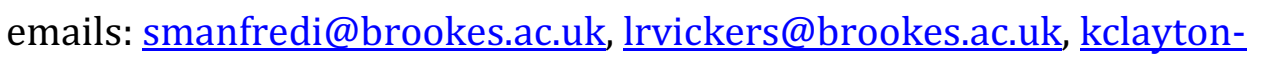
hathway@brookes.ac.uk 


\section{Introduction}

The Public Sector Equality Duty (PSED), created by the Equality Act 2010, has had a very mixed reception. Welcomed by some as having the potential to create comprehensive and transformative equality ${ }^{1}$ and enhance social justice, it has at the same time been subject to somewhat negative scrutiny. Concerns about the adequacies of enforcement have come from equality practitioners and academics, and Government has criticised the supposed bureaucratic burden it creates for public sector organisations. This led the previous Coalition Government to commission a review of the PSED, which concluded that the PSED was not operating as intended. In particular the review group could find few concrete examples of the PSED improving outcomes; and compliance processes could be bureaucratic, leading to a 'tick box' approach by many organisations. The review of the PSED reported in September $2013^{2}$ concluded that the PSED should be retained for now, but a further review should take place in 2016.

However, this second review has not happened. Moreover, following the political developments after the EU referendum in the UK, Prime Minister Theresa May put tackling disadvantage and discrimination back on the government agenda, ordering a race audit of public services. ${ }^{3}$ The importance of the PSED in promoting equality was also stressed by the Women and Equalities Parliamentary Select Committee in November $2016 .{ }^{4}$ Thus, it may be that the PSED will be given a reprieve.

It is within this context that this article offers a novel review of how the PSED works in practice and provides fresh insights into some of its strengths and weaknesses as a regulatory model for pursuing equality. In particular we propose that the deliberative and participatory processes that have, in some cases, been introduced as a response to the PSED, can in themselves be viewed as equality outcomes.

The PSED was designed to change the systems that operate in organisations, so that the pursuit of equality aims would be mainstreamed, and following the implementation of the duty in individual organisations and sectors, there is plenty of evidence that a degree of mainstreaming is occurring. Moreover, when one considers the duty as a

\footnotetext{
${ }^{1}$ B. Hepple, 'The New Single Equality Act in Britain' (2010) 5 The Equal Rights Review 11.

${ }^{2}$ Government Equalities Office - Independent Steering Committee (2013) Review of the Public Sector Equality Duty: Report of the Independent Steering Group. Available at: www.gov.uk/government/publications/the-independent-steering-groups-report-of-the-public-sectorequality-duty-psed-review-and-government-response (Accessed: 7 July 2017).

3 Theresa May launches race audit of public services. BBC News 27 August 2016 http://www.bbc.co.uk/news/uk-politics-37194207 (Accessed: 7 July 2017).

${ }^{4}$ More Transparency Needed from HM Treasury on Equality Analysis. 18 November 2016 https://www.parliament.uk/business/committees/committees-a-z/commons-select/women-andequalities-committee/news-parliament-2015/hm-treasury-equality-analysis-report-16-17 (accessed 3rd February 2017).
} 
form of second-generation regulation, ${ }^{5}$ in which the aims are to alter the behaviour of the regulated party prospectively, rather than to enforce rules following their breach, then the processes introduced by the PSED can be shown to be somewhat more effective than is at first supposed.

In what follows, we assess the effectiveness of the PSED, examining some of the criticisms, and offering an assessment based on insights from debates within equality law as well as examples of its practical implementation. We start with a focus on the aims of the PSED, before examining the regulatory mechanisms used to implement the Duty and the academic concerns which have been levelled at the use of these more indirect regulatory mechanisms in the context of equality and labour law. We then consider some of the evidence on the implementation of the PSED in practice to assess whether and to what extent the PSED can claim to be effective and whether academics' concerns about the reflexive turn in equality law are warranted. Finally, we consider what can be learned from the implementation of the PSED, and suggest ways in which its processes might be improved to increase its effectiveness as a regulatory mechanism.

\section{The aims of the PSED}

The aim of the PSED was to mainstream equality, drawing on the earlier generation of positive duties which were contained in early race relations legislation, ${ }^{6}$ and consolidated during the late 1990s and 2000s. ${ }^{7}$ In the Equality Act 2010 the PSED was expanded to cover all the equality grounds as part of a process of harmonizing equality law. The Public Sector Equality Duty can be viewed as part of a project to create what Bob Hepple termed 'transformative equality', 8 in which public bodies mainstream equality so that it permeates all their activities. The aim of the legislation is to make the promotion of equality on all the equality grounds central to the work of public authorities, so that they take account of equality in the day-to-day work of policymaking, service delivery, employment practice and other functions.

Section 149 Equality Act 2010 provides:

(1) A public authority must, in the exercise of its functions, have due regard to the need to-

\footnotetext{
5 J. Black, 'Proceduralizing Regulation Part I' (2000) 20 0JLS 597; S. Sturm, 'Remedying Organizational Discrimination', in Legality and Community: On the Intellectual Legacy of Philip Selznick (R. Kagan, M. Krygier, and K. Wilson, (Eds) (Maryland: Rowman and Littlefield Publishers, 2002); K. Yeung, Securing Compliance, A Principled Approach (Oxford: Hart, 2004).

${ }^{6}$ See J. Rivers, 'Promoting Religious Equality' (2012) 1 Oxford Journal of Law and Religion 386 for a brief history of the equality duties.

7 Section 75 Northern Ireland Act 1998 placed a range of equality duties on public bodies. The Government of Wales Act 1998, and The Greater London Authority Act 1999 also placed equality duties on the Welsh Assembly and the Greater London Authority; Race Relations (Amendment) Act 2000; Disability Discrimination Act 2005; Equality Act 2006, amending the Sex Discrimination Act 1975.

${ }^{8}$ B. Hepple, (2010) ibid., at fn. 1.
} 
(a) eliminate discrimination, harassment, victimisation and any other conduct that is prohibited by or under this Act;

(b) advance equality of opportunity between persons who share a relevant protected characteristic and persons who do not share it;

(c) foster good relations between persons who share a relevant protected characteristic and persons who do not share it....

(3) Having due regard to the need to advance equality of opportunity...involves having due regard, in particular, to the need to ...

(c) encourage persons who share a relevant protected characteristic to participate in public life or in any other activity in which participation by such persons is disproportionately low...

(5) Having due regard to the need to foster good relations between persons who share a relevant protected characteristic and persons who do not share it involves having due regard, in particular, to the need to-

(a) tackle prejudice, and

(b) promote understanding.

The s149 Duty is supplemented by specific duties which are designed to ensure better performance of the general duty. However, the specific duties have been substantially scaled back since 2010, and in England they require the specified public bodies only to publish information demonstrating their compliance with the equality duty and to publish equality objectives. ${ }^{9}$ The specific duties are fuller in Scotland and Wales and include duties to publish reports on progress and to prepare equality outcomes with the engagement of relevant groups such as disabled service users. ${ }^{10}$

Although one might summarise the aim of the PSED and the specific duties ${ }^{11}$ as broadly to promote equality between different groups, the meaning of the term 'equality' has itself been the subject of extensive academic debate. ${ }^{12}$ The concept of equality that is embedded in the duty is complex, and reflects much of that debate. The 2010 Act was introduced following 13 years of research and campaigning, ${ }^{13}$ including a number of independent research projects ${ }^{14}$ and government reviews ${ }^{15}$ exploring the need for

\footnotetext{
${ }^{9}$ S. Fredman 'The Public Sector Equality Duty' (2011) 40 Industrial Law Journal 405.

${ }^{10}$ The Equality Act 2010 (Statutory Duties) (Wales) Regulations 2011, The Equality Act 2010 (Specific

Duties) (Scotland) Regulations 2012 and The Equality Act 2010 (Specific Duties) Regulations 2011.

${ }^{11}$ For the purposes of the discussion that follows, the PSED will be taken to include the specific equality duties.

${ }^{12}$ See for example, C. O'Cinneide, 'Fumbling Towards Coherence: The Slow Evolution of Equality and AntiDiscrimination Law in Britain' (2006) NILQ 57, C. Barnard and B. Hepple, 'Substantive Equality' (2000) 59 CLJ 562, S. Fredman, Discrimination Law (Oxford: OUP, 2002), B. Hepple, 'The Aims of Equality Law' in C. O'Cinneide and J. Holder (eds) Current Legal Problems (Oxford: OUP, 2008). See also N. Fraser, 'Rethinking Recognition' (2000) 3 New Left Review 107, and C. Taylor, Multiculturalism and 'The Politics of Recognition (Princeton: Princeton University Press, 1992).

${ }^{13}$ For a history of the introduction of the Equality Act 2010 see B. Hepple, Equality: The new legal framework (Oxford: Hart, 2014) p2 ff.

${ }^{14}$ B. Hepple, M. Coussey and T. Choudhury Equality: A new framework. Report of the Independent Review of Enforcement of UK Anti-Discrimination Legislation (Oxford: Hart 2000).
} 
reform of the equality law framework. Some development in thinking on equality could already be seen in the 2006 Equality Act; ${ }^{16}$ and with the new harmonised Equality Act 2010 some significant advances can be seen, including a comprehensive vision of equality moving beyond the traditional ideas of formal and substantive equality that underpin the understanding of direct and indirect discrimination.

The notion of equality used in the 2010 Act encompasses ideas of recognition and dignity as well as concepts of redistribution, both well-developed conceptions of equality. Fraser among others ${ }^{17}$ recognised that inequality is not limited to socioeconomic inequality but can also be understood in cultural and symbolic terms. Thus people will only be fully equal if they develop a sense of personal identity and have that identity recognised and respected by society. ${ }^{18}$ Moreover, equality has been understood in terms of redistribution and the redressing of disadvantage. ${ }^{19}$ Both these models of equality can be seen in the PSED, with its focus on tackling prejudice, fostering good relations and eliminating discrimination and disadvantage.

In addition, the PSED moves beyond these concepts of equality to reflect a more comprehensive definition, a model of equality that is based on the idea of inclusion. It embraces both recognition and disadvantage, and yet moves beyond this, aiming to end marginalisation and disadvantage of groups, and thereby to enhance dignity. This inclusionary and participatory notion of equality can be traced to the work of Fredman and Collins, among others. For example, in 2002 Fredman developed the notion of equality to include breaking the cycle of disadvantage associated with groups sharing a protected characteristic; recognising, affirming, and accommodating different identities; facilitating full participation in society; and promoting respect for the equal dignity and worth of all, redressing stigma, stereotyping, humiliation and violence because of membership of such a group. ${ }^{20}$ Collins too suggests that social inclusion should inform our understanding of equality, to be achieved by encouraging minority or disadvantaged groups to participate in civic life, so that their voice within the community can become stronger. ${ }^{21}$

The PSED as defined in s 149 Equality Act clearly adopts this more comprehensive understanding of equality. As well as requiring the elimination of discrimination and the fostering of good relations, the definition includes elements of Fredman's 2002 vision.

\footnotetext{
15 Fairness and Freedom: The final report of the Equalities Review, Department of Communities and Local Government, 2007; Discrimination Law Review: A framework for Fairness. Proposals for a Single Equality Act, Department of Communities and Local Government, 2007.

${ }^{16}$ A more comprehensive vision of equality had already started to emerge in earlier reforms to Equality law, for example, in section 3 Equality Act 2006.

17 See N. Fraser (2000) ibid., fn 12 and C. Taylor (1992) ibid., at fn 12.

18 N. Fraser, 'From Redistribution to Recognition? Dilemmas of Justice in a 'Post-Socialist' Age' (1995)

1/212 New Left Review 68.

${ }^{19}$ C. Taylor (1992) ibid., fn. 12.

${ }^{20}$ S. Fredman, The Future of Equality in Britain (Manchester: Equal Opportunities Commission, 2002).

${ }^{21}$ H. Collins, 'Discrimination, Equality and Social Inclusion' (2003) 66 MLR 16.
} 
Section 149 (3) and (5) sets out more clearly that what is required is the encouragement of participation in public life or in other activity, where participation by those with a protected characteristic is disproportionately low; as well as tackling prejudice and promoting understanding.

Given the aspirational nature of some of its aims, it is not surprising that the PSED also involves a different enforcement mechanism from that adopted by other parts of the equality legislation. Although partly enforceable through the intervention of the Equality and Human Rights Commission and court processes, the PSED is designed as second-generation regulation, which aims to achieve a culture of compliance, rather than relying on coercive court proceedings. These regulatory mechanisms, and their fit with the PSED are now discussed.

\section{Second-generation regulation and reflexive law}

Not only does the PSED include an enhanced definition of the concept of equality, it also develops further the use of second-generation regulatory mechanisms to achieve its aims, rather than relying on complaints led enforcement mechanisms to ensure compliance with equality law. Limitations of the traditional complaints-led model include the short lived effect of individual cases in leading to systemic organisational change and its failure to eradicate institutionalised inequality, or to lead to transformational change. ${ }^{22}$ Instead, a second-generation of regulation has developed which relies less on enforcement by the state through the courts, and more on responsive proceduralized self-regulation, in which compliance is based on developing the capacity of institutions to address inequality. In the case of the PSED, public sector organisations are required not only to eliminate discrimination, an aim that arguably might be achieved by a complaints-led mechanism, but also to advance equality, foster good relations and encourage participation in public life, aims that can only be achieved by organisational change and proactive steps.

A number of second-generation models of regulation exist, and a full description and critique of each is beyond the scope of this article. However, a common thread of these mechanisms is that they focus on altering the internal workings of the regulated organisation. The aim is that these internal mechanisms will ensure that the aims of the legislation are implemented, as opposed to ensuring that a number of pre-set rules can be enforced. ${ }^{23}$ The focus is on using the law to structure organisations' decision making processes to achieve equality aims, rather than imposing any particular substantive ends on those organisations. ${ }^{24}$ Such second-generation regulatory mechanisms aim to be participative and deliberative, thereby ensuring their effectiveness as they can draw

\footnotetext{
${ }^{22}$ B. Hepple 'Enforcing Equality Law: Two Steps Forward and Two Steps Backwards of Reflexive Regulation' (2011) 40 Industrial Law Journal 321; C. McLaughlin, 'Equal Pay, Litigation and Reflexive Regulation: The Case of the UK Local Authority Sector' (2014) 43 Industrial Law Journal 1.

23 See K. Yeung (2004) ibid., at p. 12.

24 J. Black (2000) ibid., at fn. 5 at p. 601.
} 
on the experience of those with the best practical knowledge and experience of any obstacles to implementation. ${ }^{25}$

One form of second-generation regulation that has been discussed in recent academic literature on discrimination law and labour law is 'reflexive law', an approach to regulation which relies on the language of systems theory, originally developed within the natural sciences, and derived from the biological theory of living systems (autopoiesis). The theory was adapted and applied to legal systems by Teubner, ${ }^{26}$ who argues that society is not structured hierarchically with law at the top, but rather, as in the natural world, society is made up of multiple systems such as the workplace, and the market, and these operate autonomously according to their own language and internal logic. Because the separate systems do not respond directly to each other, a direct command from one system, such as the law, to another system, such as the workplace, may not achieve its aims, resulting in what Teubner calls the 'regulatory trilemma', ${ }^{27}$ whereby legal intervention is ignored or is counterproductive. ${ }^{28}$ Systems theory suggests that top-down command and control methods of legal regulation will be ineffective in changing organisations, because the legal system and the work system are separate and operate in different 'languages'. The solution is to develop 'reflexive law' with a focus on working within the logic of the different systems and adjusting and altering their environment to achieve one's aims. The idea is that organisations will change when they are able to operate within their own 'language', with the role of law being to act as an external stimulus to prompt self-regulation.

Applying the language of systems theory to the PSED, the duty acts as a stimulus to the sub-system of the public authority, and is translated and interpreted according to its norms. The PSED does not dictate any particular outcome; instead it seeks to encourage workplaces and organisations to introduce processes and procedures within their own systems that will help them achieve the objectives of the Duty. ${ }^{29}$

The application of 'reflexive law' to the discrimination context has been the subject of much academic discussion, including deliberation on what is needed for regulation of this type to be more effective in the field of equality law. ${ }^{30}$ Hepple has suggested that in the equality law context, effective reflexive regulation requires a triangle of three 'interlocking mechanisms': first, scrutiny by the organisation itself to ensure effective

\footnotetext{
25 See J. Black (2000) ibid., at fn. 5 at p. 613 who states that 'forms of law that promote deliberation have a natural advantage'.

${ }^{26}$ G. Teubner Law as an Autopoietic System (Oxford: Blackwell 1992).

27 G. Teubner, 'After Privitization: the Many Autonomies of Private Law' (1998) 51 Current Legal Problems 406; See S. Fredman (2011) ibid at fn. 9.

${ }^{28}$ B. Hepple (2011) ibid., at fn 22; S. Fredman (2011) ibid., at fn. 9.

${ }^{29}$ See S. Fredman (2011) ibid., at fn. 9.

${ }^{30}$ B. Hepple (2011) ibid., at fn 22; S. Deakin and C. McLaughlin, 'The Regulation of Women's Pay: From Individual Rights to Reflexive Law?' (2007) Centre for Business Research, University of Cambridge, Working Paper No. 350; C. McCrudden, 'Equality Legislation and Reflexive Regulation: A Response to the Discrimination Law Review's Consultative Paper' (2007) 36 Industrial Law Journal 255; S. Fredman (2011) ibid., at fn. 9; C. McLaughlin (2014) ibid., at fn 22.
} 
self-regulation; second, the involvement of interest groups (such as managers, employees and service users) who must be informed, consulted and engaged in the process of change'; and third 'an enforcement agency (such as EHRC) which should provide the back-up role of assistance, building capabilities and ultimately sanction where voluntary methods fail'. ${ }^{31}$ These three interlocking mechanisms create a

'triangular relationship among those regulated (e.g. the public authority), others whose interests are affected (e.g. workers and consumers) and the enforcement agency as the guardian of the public interest'. ${ }^{32}$

Others have noted that if reflexive regulation is to be effective, bridging mechanisms are needed to assist what is termed the 'structural coupling' 33 between the legal system and the organisations in which the rules are to apply. In the equality context, such mechanisms could include workplace consultation, or consultation with service users.

Bridging mechanisms, along with elements of Hepple's triangle can be seen in the structure of the PSED. Enforcement is provided through the EHRC and judicial review processes; and encouragement for self-scrutiny is present through the requirement under the specific duties to collect data. Although the requirement for involvement of equality groups has been reduced in England since 2010, case law suggests that such consultation remains desirable. ${ }^{34}$ Consultation with employees and with stakeholders also creates the bridging mechanisms needed to link the legal requirements with organisations on the ground.

This neat fit with models of second-generation regulation in general, and reflexive regulation in the form suggested by Hepple and others in particular is, of course, no surprise, as the new PSED was so designed. ${ }^{35}$ Rather than setting out a solution and requiring the organisation to implement it, the duty puts an onus on the organisation to have due regard to the relevant issues and come up with its own individually tailored response. ${ }^{36}$ Although organisations will no doubt wish to draw on established benchmarking and good practice, 37 the exact requirements of how to meet the duty are not set out. This can mean that this form of regulation appears uncertain and to lack clarity, although the inherent flexibility of the regulatory framework can enable responses to be formulated which best fit the organisational structure and culture. ${ }^{38}$

\footnotetext{
${ }^{31}$ B. Hepple (2011) ibid., at fn 22.

32 B. Hepple (2011) ibid., at fn 22.

${ }^{33}$ C. Barnard, S. Deakin and R. Hobbs, 'Opting-out of the 48-week: Employer Necessity or Individual Choice? An Empirical Study of the Operation of Article 18(1)(b) of the Working Time Directive in the UK' (2003) 32 Industrial Law Journal 223, cited in S. Deakin and C. McLaughlin (2007) ibid., at fn 30.

34 The requirements of the specific duties in Scotland and Wales still require the involvement of relevant groups in the development of objectives.

${ }^{35}$ C. McCrudden, ibid., at fn. 30; S. Fredman (2011) ibid at fn. 9.

${ }^{36}$ S. Fredman (2011) ibid at fn. 9.

37 S. Deakin and C. McLaughlin (2007) ibid at fn. 30.

38 See K. Yeung (2004) ibid. at fn. 5.
} 
The PSED is an archetypal example of second-generation regulation. Instead of imposing a top down rule on organisations, the requirement to comply with the PSED is designed to provide a stimulus to the organisation to develop its own response. Ideally this should lead to solutions that are culturally more suited to the organisation and thus more likely to be followed. However, although the theory may seem attractive, this 'reflexive turn' in equality law ${ }^{39}$ has given rise to some significant criticism.

\section{A. Concerns about the 'reflexive turn' in equality law}

Some practical concerns have been expressed regarding the efficacy of the PSED to enhance equality outcomes. The first arises from the failure of a number of legal cases in which groups or individuals have sought to enforce the duty. ${ }^{40}$ Results have been mixed for cases where judicial review has been sought for failure to comply with the Duty. Cases have involved issues such as a failure to have due regard for race equality in making planning decisions, ${ }^{41}$ challenges to the funding for domestic violence support, ${ }^{42}$ and challenges to government policy such as the cancellation of the building for schools programme ${ }^{43}$ and the budget. ${ }^{44}$ Even where there has been a finding that the duty has not been complied with, the result has rarely been the overturning of the original decision. The focus has been on procedural matters, and ensuring that equality issues were addressed at the decision-making stage, rather than on reassessing the outcomes of decisions from an equality perspective. In addition, the standard of review ('due regard') can be said to be too low to really lead to the active pursuit of equality in the public sector. 45

A second practical issue relates to the bureaucratic responses developed by public bodies in order to comply with the PSED, which have focussed more on procedure than on removing the inequality in question. ${ }^{46}$ This 'tick box' response enables public bodies to show that they have considered equality issues, rather than focusing on the impact of decisions made, and whether they have been altered to ensure that equality issues are properly addressed.

\footnotetext{
${ }^{39}$ D. Ashiagbor, 'Evaluating the Reflexive Turn in Labour Law' in A. Bogg, C. Costello, A. Davies, and J. Prassl, (eds.) The Autonomy of Labour Law (Oxford: Hart Publishing, 2015) 123.

${ }^{40}$ For an account of the case law, see S. Fredman, (2011) ibid., at fn. 9; M. Bell, 'Judicial enforcement of the duties on public authorities to promote equality' (2010) Public Law 672; A. McColgan, 'Litigating the Public Sector Equality Duty: The Story So Far' (2015) 35 Oxford Journal of Legal Studies 453.

${ }^{41}$ See for example $R$ (on the application of Janet Harris) v Haringey London Borough Counciland others [2010] EWCA Civ 703.

${ }^{42} R$ (on the application of (1) Kaur (2) Shah (Claimants) $v$ Ealing London Borough Council (Defendant) \& Equality \& Human Rights Commission (Intervenor) [2008] EWHC 2062 (Admin).

${ }^{43} R$ (on the applic. of Luton BC and others) v SS for Education [2011] EWHC 217 (Admin).

${ }^{44} R$ (on the applic. of Fawcett Society) $v$ Chancellor of the Exchequer [2010] EWHC 3522 (Admin).

${ }^{45}$ S. Fredman (2011) ibid., at fn. 9; S. Fredman, 'Addressing Disparate Impact: Indirect Discrimination and the Public Sector Equality Duty' (2014) 43 Industrial Law Journal 349.

${ }^{46}$ See for example, S. Fredman, 'Positive duties and socio-economic disadvantage: bringing disadvantage onto the equality agenda' (2010) EHRLR 290; and Fairness and Freedom: the final report of the Equalities Review, February 2007

http://archive.cabinetoffice.gov.uk/equalitiesreview/upload/assets/www.theequalitiesreview.org.uk/eq uality review.pdf (accessed 7 July 2017).
} 
In addition to these more practical reservations, some deeper concerns can be identified. One relates to the identification of relevant stakeholders within organisations or beyond. Fredman has questioned whether deliberative models of regulation, based on consultation with unspecified stakeholders are capable of achieving substantive equality. ${ }^{47}$ This has been raised as a particular concern in the context of the extension of the PSED to new grounds such as religion and belief, as it is unclear who should be accepted as the relevant stakeholder from many religious individuals or groups. ${ }^{48}$

A second concern relates to the inequality of bargaining power that can occur within any consultation with stakeholders. Although there is no longer an explicit duty to consult with stakeholders in implementing the PSED in England, case law on the PSED suggests that public bodies should undertake some consultation with stakeholders when devising policy. ${ }^{49}$ However, the duty has little to say about how equality of bargaining power is ensured within that consultation. ${ }^{50}$

More generalised reservations have also been raised about the use of reflexive regulation in the equality context. McCrudden identifies a number of issues, ${ }^{51}$ in particular that reflexive regulation may insufficiently recognise the conflicting political and economic interests that are in play when considering equality in the public sector. Reflexive regulation can allow for failures to meet the standards required to be put down to a somewhat neutrally termed 'communication failure', rather than looking to the political and power relations at stake. This concern is echoed by Ashiagbor ${ }^{52}$ who fears that the move to reflexive regulation runs in parallel to and even reinforces the neoliberal turn in economic policy. The focus can turn to the process of implementation, rather than on the content of the rights being implemented, with the result that equality outcomes remain vulnerable. The concern is shared by Black ${ }^{53}$ who points out that the new regulatory mechanisms can divert attention from the values that are pursued, by focusing instead on the mechanisms for delivery and implementation. Thus, even policies that run counter to equality can claim to accord with the PSED on the basis that the organisation had fulfilled its procedural requirement to have 'due regard' to the need to promote equality, but decided to press ahead with the policy nonetheless.

The failure of reflexive regulation to recognise the inequality of power relations within organisations has led Fredman ${ }^{54}$ to suggest that the PSED may be a fragile platform from which to attack government policy, as it does not require a change in policy as a response, even where a claim is successful. The power relations in play may not only

\footnotetext{
${ }^{47}$ S. Fredman, (2011) ibid., at fn. 9.

${ }^{48}$ A. Lester, and P. Uccellari, 'Extending the Equality Duty to Religion, Conscience and Belief: Proceed with Caution', (2008) 5 EHRLR 567; L. Vickers, 'Promoting Equality or Fostering Resentment? The Public Sector Equality Duty and Religion and Belief' (2011) 31 Legal Studies 135.

${ }^{49} R(L H)$ v Shropshire Council [2014] EWCA Civ 404.

50 B. Hepple (2014) ibid. at fn. 13, at p. 166.

${ }^{51}$ C. McCrudden, (2007) ibid., at fn. 30.

${ }^{52}$ Ashiagbor, D. 'Evaluating the Reflexive Turn in Labour Law' (2015) ibid., at fn 39.

53 J. Black (2000) ibid., at fn. 5 at 598.

${ }^{54}$ S. Fredman (2011) ibid., at fn. 9.
} 
involve government; unequal power relations also exist, of course, between organisations and their workforce. Barmes and Ashtiany 55 have pointed out that the diversity agenda can sometimes be used to achieve managerial aims, without core commitment to changing values within the organisation.

In effect, then, the concern is that reflexive regulation does not address deep structural inequalities and the inequality of power relations operating within organisations. Instead, as with other forms of second-generation regulation, the implementation of social tasks that should be the concern of the state, such as the development of institutional equality, is externalised to become an internal organisational interest, albeit within the public sector.

The concerns raised regarding the use of second-generation regulatory mechanisms such as reflexive law to deliver equality can be grouped into three broad areas: concerns related to process, such as the representativeness of any consultation; practical concerns regarding enforcement; and deeper concerns regarding the capacity for regulation to challenge or even to reinforce the neo-liberal turn in economic policies which may be at the root of inequality. In the next section, we consider some examples from the empirical evidence about implementation of the duty within organisations, in order to assess whether and to what extent these concerns can be allayed.

\section{Assessing the effectiveness of the PSED}

\section{A. The duty in practice}

The review of the PSED undertaken in 2013 together with the subsequent review of the duty in Wales, published in 2014, provides a bank of evidence about the working of the PSED. This documentation was the starting point of our desk-based search to locate available evidence about the implementation of the PSED. We were able to access most of this documentation from the government web-pages ${ }^{56}$ which comprise the following: over 100 submissions to the PSED consultation primarily from public authorities and other organisations affected by the Duty; summaries of evidence collected by those involved in the government review through a series of roundtable discussions and site visits with a range of stakeholders; research commissioned by the government and undertaken by independent researchers; the final government report presenting the results of the review.

In order to review this evidence and gain an understanding of how the duty is working in practice, we developed two sets of inclusion criteria to select a sample of documentation from the government web-site. The first set of inclusion criteria aimed to ensure that the selected documentation captured the perspectives of a wide range of stakeholders from different sectors and linked to this that it represented different types

${ }^{55}$ E. Barmes, and S. Ashtiany, 'The Diversity Approach to Achieving Equality: Potential and Pitfalls' (2003) 32 Industrial Law Journal 274.

${ }^{56}$ https://www.gov.uk/government/publications/the-independent-steering-groups-report-of-thepublic-sector-equality-duty-psed-review-and-government-response [accessed 7 July 2017]. 
of available evidence (e.g. self-reported evidence, independent studies and summaries of roundtable discussions). From the self-reported evidence which amounted to over 100 submission we selected a sample of documentation which represented large interest groups either subject or affected by the duty such as public sector authorities, health authorities, Office of the Children's Commissioner, Citizens Advice Bureau, Trade Unions, the Equality and Diversity Forum and academics with equality expertise. We found that the summaries of the roundtable discussions and site-visits were of special interest as they involved voluntary and community sector organisations supporting groups with protected characteristics, discrimination lawyers, private sector large and small suppliers to central and local government, inspectorates and regulatory bodies, and public sector legal advisers. Thus these offered a wide range of perspectives from different stakeholders and complemented the research report, published in 2013,57 which had been commissioned by the Government Equalities Office and which focused on large organisations and equality specialists.

The second set of criteria were distilled from our analysis of the concerns raised within the academic literature on the PSED, discussed above, which enabled us to identify three key themes: consultation and identification of stakeholders; enforcement; and power relations. These three themes guided our search for examples from the selected evidence. It is important to stress that the purpose of our review was to identify examples which show how the duty can work in practice with regard to the themes that we identified and that it was not our intention to measure the prevalence of the examples selected.

Finally in order to complement the above sample of evidence selected from the documentation gathered and research undertaken as part of the Government's PSED review, we also considered the study on the implementation of duty in Wales, undertaken in 2014; case law; other externally validated sector specific equality standards and initiatives, such as the Equality Framework for Local Government; and other academic evidence, in order to gain a more comprehensive picture of the duty in practice.

What follows discusses a number of typical examples selected from this evidence to look at the way the duty has been implemented and experienced in practice and to gain an insight into the strengths and weaknesses of this type of regulatory model.

\footnotetext{
572013 NatCen report 'Views and Experiences of the Public Sector Equality Duty (PSED)' (available at https://www.gov.uk/government/uploads/system/uploads/attachment data/file/237200/PSED Revise d Report Final 030913 - FINAL.PDF, accessed 7 July 2017). This study was commissioned by the Government to inform the 2013 review of the PSED but due to resources and time restrictions the researchers were not able to provide a range of wider experiences about the implementation of the PSED (p.12). The study concluded that the PSED 'was working well or had the potential to do so' (p.5). However, the vast majority of those who took part in this research were equality and diversity practitioners (p.55) likely to be supportive of the duty.
} 


\section{i. Process}

One of the key features of the Duty is the expectation of consultation, 58 Hepple's second 'interlocking mechanism'. This improves the quality of the decision-making by incorporating those who are affected into the decision-making process. This results in a form of deliberative democracy, 'whereby interests are not taken as fixed or predetermined, but are themselves moulded by the process of decision-making'. ${ }^{9}$ For this to be achieved, the process of consultation and the identification of stakeholders must work well.

The identification of the stakeholders may be easier when dealing with a clearly defined environment such as the workplace. Public sector employers who took part in the consultation often reported that they identify stakeholders through staff equality networks representing employees with different protected characteristics, or use the Duty to create such forums, or consult with trade unions to reach interested groups. 60 Trade unions also reported using the duty in their negotiations with employers to secure better outcomes for the workforce. ${ }^{61}$ However, the identification of stakeholders in the context of service delivery may be more challenging. Since this function affects a large number of users it can be more difficult for a local authority to consult all the relevant stakeholders. As a result, there is a risk that only the best organised groups are likely to have their voices heard in a consultation process ${ }^{62}$, while those less organised, which possibly include more vulnerable individuals, end up being excluded from the process of consultation.

However, even in the broader context of service delivery examples of good practice can be identified. For example, one local authority reported the establishment of a social cohesion forum which includes approximately 78 different organisations and 16 community networks consisting of different BME groups. ${ }^{63}$ Not only does this forum provide a space for these groups to be consulted on matters that affect them, but also the setting up of such consultative structures has enabled the promotion of a better understanding among these groups. In effect, the requirement of consultation can

${ }^{58}$ R(LH) v Shropshire Council [2014] EWCA Civ 404.

${ }^{59}$ S. Fredman, Discrimination Law (Oxford: OUP, 2011) at p. 318.

${ }^{60}$ Review of the Public Sector Equality Duty (PSED) Note of Site Visit: A City Council (a) and (b)

(undated); Note of Roundtable: Claimant Lawyers 26 March 2013

https://www.gov.uk/government/uploads/system/uploads/attachment data/file/249362/Round table write ups.zip (accessed 7 July 2017).

61 Note of Roundtable: Claimant Lawyers 26 March 2013

https://www.gov.uk/government/uploads/system/uploads/attachment data/file/249362/Round table write ups.zip (accessed 7 July 2017); Public Sector Equality Duty, TUC Response Call for Evidence 19

April 2013 https://www.gov.uk/government/publications/the-independent-steering-groups-report-ofthe-public-sector-equality-duty-psed-review-and-government-response [accessed 7 July 2017].

62 Review of the Public Sector Equality Duty (PSED) Note of Site Visit: A City Council (a): 5 https://www.gov.uk/government/uploads/system/uploads/attachment data/file/249362/Round table write ups.zip [accessed 7 July 2017].

${ }^{63}$ Review of the Public Sector Equality Duty (PSED) Note of Site Visit: A City Council:

https://www.gov.uk/government/uploads/system/uploads/attachment data/file/249362/Round table write ups.zip [accessed 7 July 2017]. 
present the double benefit of creating a space where groups can have their voices heard by decision makers, as well as offering the opportunity to foster good relations among different groups.

Moreover, as more individuals and organisations become aware of the duty, they are empowered by it to hold public authorities to account for their decisions and consider the impact that these can have on different groups. Increasingly small voluntary groups representing the interests of vulnerable people whose voices otherwise would not be heard are using the Duty to hold public authorities to account. A notable example can be seen from the case law: the Fawcett Society, a small third-sector feminist organisation, used the gender equality duty to challenge the coalition government austerity budget in 2010 on the grounds that it would have a disproportionate negative impact on women. The case serves as an example of how second-generation regulation can provide opportunities for new actors and social movements to play a role in challenging inequalities. 64

It is difficult to draw firm conclusions about the actual quality of the consultation process and the extent to which interested groups are able to take part and influence the decision making process beyond just being consulted. On the one hand some local authorities have reported 'consultation fatigue', with representatives of interested groups feeling that they are being over-consulted.65 On the other hand, more meaningful consultation processes can be identified. For example, bringing chairs of equalities networks into the council's strategic board was reported to be very helpful in terms of making every officer aware, ${ }^{66}$ and embedding the duty in the decision making process.

Thus, although there can be challenges for public authorities in identifying relevant stakeholders and in establishing meaningful processes of consultation, nonetheless positive examples can be found which suggest that the participative dimension of the duty can be achieved. One of the most significant features is that of empowering groups and social movements to hold public authorities to account.

\section{ii. Enforcement}

As mentioned above, the enforcement of the duty can take place at two levels. The first is at an organisational level through the development of self-regulation. The second is remedial in nature and takes place through the process of judicial review. We look at these two levels of enforcement in turn.

${ }^{64}$ H. Conley, 'Using Equality to Challenge Austerity: New Actors, Old Problems' (2012) 26 Work, Employment and Society 349.

${ }^{65}$ Equality and Human Rights Commission Wales (2014) Review of the Public Sector Equality Duty: 10 available at https://www.equalityhumanrights.com/en/publication-download/review-public-sectorequality-duty-psed-wales-full-report (accessed 5th January 2016).

${ }^{66}$ Review of the Public Sector Equality Duty (PSED) Note of Site Visit: A County Council (a): 4

https://www.gov.uk/government/uploads/system/uploads/attachment data/file/249362/Round table write ups.zip [accessed 7 July 2017]. 


\section{Enforcement by self-regulation}

Public authorities who took part in the consultation exercise maintained that they were taking a range of actions in response to the Duty. A typical response is to improve data collection and monitoring systems in order to identify disadvantaged groups, leading to the review of services in order to ensure better equality outcomes for these groups. For example, data relating to exclusions was reported to have helped understanding of this issue within the school system; ${ }^{67}$ equalities data used to monitor increasing numbers of homelessness applications from women was said to have led to a change in provision previously aimed at men; 68 and the Merseyside Fire and Rescue Authority reported that they had used statistics on age and deprivation to map those at greater risk from fire. This revealed that older people are particularly vulnerable to fire and enabled prevention and protection resources to be targeted at those at greatest risk, leading to a significant reduction in fires in the home in the area. ${ }^{69}$ Other examples of action that those consulted had taken to implement the Duty involve the employment of equality practitioners and the appointment of 'equality champions' to provide leadership and expertise. These have provided a framework and focus for action. In addition, studies by the EHRC have found that employment monitoring, review and reporting duties, when undertaken rigorously and systematically, have led to transparency and accountability; ${ }^{70}$ and the Government Equalities Office review found that equality training has been used to build capabilities and mainstream equality so that it permeates all activities across the different levels of the organisation. ${ }^{71}$ Thus, although sometimes criticised as bureaucratic, there is evidence that the internal processes introduced to comply with the duty have led to change within organisational systems.

In addition to the processes introduced by organisations to develop self-regulation, other equality measures have made a significant contribution to achieving equality outcomes. Thus, although the PSED is a useful lever for embedding change, some authorities prefer other externally validated equality standards, ${ }^{72}$ such as the Equality Framework for Local Government, or the NHS Equality Delivery System (EDS). Other

\footnotetext{
${ }^{67}$ Response to the government's Equality Duty Review (Office of the Children's Commissioner, 2013) Available at: http://www.childrenscommissioner.gov.uk/content/publications/content 448 (Accessed 14th May 2013).

68 Public Sector Equality Duty: Submission to Government Equalities Office Review, (Citizens Advice Bureau, 2013). Available at: http://www.edf.org.uk/blog/?p=22172 (Accessed 7 July 2017).

${ }^{69}$ Equality and Diversity Forum (EDF) (2013). Equality and Diversity Forum Submission to the Government's Equality Duty Review. Available at: http://www.edf.org.uk/blog/?p=22172 (Accessed 7 July 2017).

70 E. Sclater, Making practice happen: Practitioners' views on the most effective specific equality duties (2009 available at http://www.edf.org.uk/wp-content/uploads/2009/02/final-report-making-practicehappen.pdf, accessed 7 July 2017).

${ }^{71}$ S. Arthur, J. Graham, K. Beninger, View and Experiences of the Public Sector Equality Duty (PSED) (2013) Government Equalities Office available at https://www.gov.uk/government/uploads/system/uploads/attachment data/file/237200/PSED Revise d Report Final 030913 - FINAL.PDF [accessed 6th October 2016].

${ }^{72}$ H. Conley, and M. Page, 'Gender Equality Duty in Local Government: The Prospects for Integration', (2010) 39 Industrial Law Journal 321.
} 
examples of sector-specific initiatives can be seen in the focus on equality issues in the regulation of health and social care services by the Care Quality Commission; ${ }^{73}$ and in Higher Education sector, where Equality Challenge Unit's Athena Swan Charter ${ }^{74}$ has been developed to advance gender equality, and where HEIs are expected to apply equality guidance when making decisions about the inclusion of staff in their submissions to the Research Excellence Framework (REF). ${ }^{75}$ In the case of the Athena Swan Charter, there is a strong financial incentive for institutions to comply since only those that have achieved silver status ${ }^{76}$ under this scheme can access some sources of research funding. ${ }^{77}$ Such initiatives are not limited to the public sector. The Investors in People ${ }^{78}$ programme which operates across the public and private sector includes as one of its standards for people management strategy that strategies should be in place for managing people that are designed to promote equality of opportunity. These sector specific and management frameworks provide further evidence of the way in which the equality duties have worked not as top-down directive legislation, but rather as reflexive regulation, in which the sub-systems develop their own normative processes and language of implementation.

Direct causal links between these schemes and the PSED are not always clear, but we suggest that its regulatory approach is likely to have created the conditions for these initiatives to develop. ${ }^{79}$ Moreover, in the case of the Research Excellence Framework the link with the PSED is explicit and can be traced back to the equality guidance issued by the Higher Education Funding Councils for the REF, which states that "the four UK higher education funding bodies have a statutory obligation as public bodies to advance equality". 80

The above examples, drawn from case law, the responses of public authorities consulted, and the implementation of sector specific equality frameworks, show that

\footnotetext{
${ }^{73}$ See http://www.cqc.org.uk/content/equality-and-human-rights accessed 7 July 2017.

${ }^{74}$ See Equality Challenge Unit Athena Swan http://www.ecu.ac.uk/equality-charter-marks/athena-swan/ accessed 7 July 2017.

${ }^{75}$ See for example the requirement to submit equality impact assessments as part of the Research Excellence Framework 2014.

www.ref.ac.uk/pubs/arrangementsforthecollectionoffinalcodesofpracticeandequalityimpactassessments $\angle$ (accessed 14 July 2016).

${ }_{76}$ This scheme is articulated in three stages: Bronze, Silver and Gold.

${ }^{77}$ See http://www.medschools.ac.uk/SiteCollectionDocuments/Letter from Dame Sally Davies Women in Science.pdf (accessed 7 July 2017).

${ }^{78}$ For details see

https://www.investorsinpeople.com/sites/default/files/Gen\%20V\%20The\%20Standard.pdf accessed 7 July 2017.

${ }^{79} \mathrm{As}$ part of the review of the PSED, organisations submitting evidence about the duty pointed to its importance, as a 'framework and catalyst for action.' See for example Disability Charities (2013) Submission to PSED Review. Available at: https://www.gov.uk/government/uploads/system/uploads/attachment data/file/85104/disabilitycharities-consortium.pdf (Accessed 7 July 2017).

${ }^{80}$ REF 0.22011 Assessment Framework and Guidance on Submissions July 2011; Section 39 Equality and Diversity p.10.

http://www.ref.ac.uk/media/ref/content/pub/assessmentframeworkandguidanceonsubmissions/GOS\% 20including\%20addendum.pdf accessed 3 February 2017).
} 
self-regulation is taking place and leading to the mainstreaming of equality. However areas where the development of self-regulation is more problematic can also be found, particularly as reported with regard to the activities of procurement and commissioning. ${ }^{81}$ The application of the PSED to procurement and commissioning appears to be less well understood, with consequent poor compliance in comparison to employee relations and service-delivery functions. An explanation for this difference can be found within systems theory, with its focus on the different 'languages' of different organisations. Employment and service delivery functions are already sensitised to equality issues through the familiarity of personnel departments with antidiscrimination legislation. As a result, they have already internalised norms and practices designed to avoid discrimination and achieve equality of opportunity. In contrast, in the case of procurement and commissioning, the language and the internal logic has been developed around a market paradigm, which seeks value for money. Therefore, not only are equality values alien to the economic discourse which is expressed purely in utilitarian terms, but they may even be conflicting with the market logic which prevails in this sub-system.

Nonetheless, some examples exist where equality considerations have been successfully integrated in the procurement process. One such example from the academic literature is the approach to equality and supplier diversity of Transport for London. ${ }^{82}$ Key aspects of the Transport for London approach include developing a clear methodology to ensure that private suppliers understand what they need to do to take equality considerations into account in a demonstrable way. This methodology requires suppliers to prepare four action plans: a strategic equality and diversity plan; an equality and diversity training plan; a supplier diversity plan; and a communication plan. Further examples can be found in the evidence submitted to the government review. One case study looked in detail at how this approach has worked in practice with one supplier shows that a 'transfer' of expertise took place as the public authority provided guidance to help the contractor prepare the required action plans. These involved raising awareness about equality considerations by developing an organisational programme called Respect. Another example of the PSED driving an equality and inclusion strategy is that of the Olympic Delivery Authority (ODA), set up to coordinate the preparation of the 2012 London Olympics. Delivery partners were subject to the PSED equality objectives which included a requirement to improve supplier diversity and this for example, led to the appointment of a small catering company run and staffed by visually impaired individuals. Moreover, the ODA used

\footnotetext{
81 Government Equalities Office - Independent Steering Committee (2013). Review of the Public Sector Equality Duty: Report of the Independent Steering Group ibid., at fn. 2. Similar findings also emerged from a review of the implementation of the PSED in Wales which identified that although 'procurement processes were being put in place...knowledge of these processes or their effectiveness was not as good as in other areas Equality and Human Rights Commission Wales (2014) Review of the Public Sector Equality Duty: 8 available at https://www.equalityhumanrights.com/en/publication-download/review-publicsector-equality-duty-psed-wales-full-report (accessed 5th January 2016).

82 See J. Lulham, 'Transport for London's approach to Equality and Supplier Diversity Through Procurement' (2011) 11 International Journal of Discrimination and the Law 99.
} 
public procurement to promote greater diversity in employment and one outcome of this was a significant increase in the number of women being employed by the construction industry for the construction of the Olympic park. The experience and learning from the ODA equality strategy have been put into practice in other major project such as CrossRail and this has determined a 'legacy' or 'ripple effect' of the PSED. ${ }^{83}$ These examples show that even in the case of procurement, identified in the government review ${ }^{84}$ as a weakness in the enforcement of the duty, cases can be found where the duty is effective: the regulatory stimulus sent to the private sector through the procurement process can set in motion a chain reaction and percolate down through the supply chain to other businesses.

In summary, the process of enforcement of the PSED via self-regulation, the first of Hepple's interlocking mechanisms, has seen areas of success. This suggests that the use of reflexive regulation as a method of enforcement can achieve equality outcomes in particular in areas that are already sensitised to equality issues such as employment and service delivery. The notes from the roundtable discussion with discrimination lawyers and voluntary and community sector organisations, reported respectively that "culture change is happening and this perceptible in practice, there have been changes to decision-making processes and procedure" and that "the PSED helped voluntary organisations by providing a framework of common understanding of equality between the public (individuals and voluntary sector organisations) and public authorities on what is required of public authorities and what the public can expect from public authorities" 85 . Moreover, examples can be found where a concern for equality has extended beyond the public sector, as the processes set up to fulfil the duty infiltrate the private sector. This has been achieved by 'translating' the duty into language to which the private sector is sensitised, such as corporate social responsibility. As highlighted by the testimony, collected during the PSED review, of a large private sector contractor that services a wide range of public sector customers: "private sector companies are as interested as the public sector in demonstrating strong values on equality and diversity". 86

The ability of the PSED to take effect beyond the public sector suggests that despite concerns about the fragility of second-generation regulatory mechanisms to achieve equality outcomes, in many cases the processes introduced as a result of the duty have permeated through the public sector, and into the private sector, particularly where the

\footnotetext{
${ }^{83}$ See T. Wright, Submission of evidence to government review of the Public Sector Equality Duty, (Centre for Research in Equality and Diversity, 2013) Available at http://www.edf.org.uk/blog/?p=22172 (Accessed 7 July 2017).

${ }^{84}$ Government Equalities Office - Independent Steering Committee (2013) ibid., at fn. 2.

85 Note of Roundtable: Claimant Lawyers 26 March 2013 and Note of Roundtable: Voluntary and

Community Sector and Trade Unions 30 January 2013

https://www.gov.uk/government/uploads/system/uploads/attachment data/file/249362/Round table write ups.zip [accessed 25 May 2017].

${ }^{86}$ Note of Site Visit: A Major Contractor, undated, https://www.gov.uk/government/uploads/system/uploads/attachment data/file/249362/Round table write ups.zip [accessed 25 May 2017].
} 
private and public sector intersect. However, despite these examples of success, reflexive regulation can certainly not be said to be a panacea: the evidence of continued inequality in work and beyond attests to that. Many equality schemes will be badly understood, under-implemented and under-resourced: fragility clearly remains.

\section{Enforcement of the PSED when self-regulation fails}

Where self-regulation fails, enforcement reverts to more traditional legal mechanisms: in the case of the PSED, judicial review can be sought. As discussed earlier the existing case law shows that where judicial review of public authorities' decisions has been undertaken the focus has been on failure to comply with procedural matters, rather than re-assessing the outcomes of a public authority's decisions. Therefore, although case law has produced useful guidance regarding how the duty should be implemented, ${ }^{87}$ the low level of scrutiny inherent in the 'due regard' standard of review means that final outcomes of these cases have rarely resulted in the overturning of the original decision. ${ }^{88}$ This suggests a serious weakness in Hepple's third mechanism, enforcement, which makes the PSED vulnerable to the possibility of non-compliance. Moreover, it is arguable that judicial review processes serve to delay important decisions. Indeed, the government review of the PSED concluded that quicker and more cost-effective ways of reconciling disputes relating to the PSED should be considered as an alternative to judicial review. ${ }^{89}$ Suggestions might be the creation of an accelerated process akin to that adopted for planning decisions; or the creation of a tribunal mechanism with the option of mediation in place of judicial review.

Yet, even though the legal processes can be slow and may not result in substantive change to their decisions, there is evidence that the process of enforcement can have an educative effect on the behaviour of public authorities. For example, lawyers who act on behalf of claimants, and who participated in the consultation, reported that public authorities are now more sensitive to equality considerations when setting budgets as a result of challenges being brought about budgetary decisions. ${ }^{90}$ The educative effect of legal cases can also be seen in Government policy on tax and benefits. Using quantitative data and fiscal analysis, the Fawcett Society demonstrated in its judicial review case that policies on tax and benefits have disproportionately disadvantaged lone mothers. In their challenge to the 2010 emergency budget, Fawcett argued that the government had failed to pay due regard to resulting inequalities. Though unsuccessful in overturning the budget, the challenge did have some practical impact as the Treasury pledged a different approach in future, and the surrounding publicity raised awareness about the need to consider differential impact on men and women across the public sector. ${ }^{91}$ The TUC also suggest that Fawcett's high-profile challenge may have led to the

\footnotetext{
${ }^{87}$ See for example, $R$ (Brown) v Secretary of State for Work \& Pensions [2008] EWHC 3158 (Admin).

88 See further S. Fredman (2011) ibid., at fn. 9.

${ }^{89}$ Government Equalities Office - Independent Steering Committee (2013) ibid., at fn. 2.

${ }^{90}$ Government Equalities Office - Independent Steering Committee (2013) ibid., at fn. 2 at p. 29.

91 D. Sands, Single Mothers: Singled Out. (London: The Fawcett Society 2011); The Impact of Austerity on Women, (London: Fawcett Society Policy Briefing, March 2012) available at:
} 
formal assessment, launched November 2010, of the extent to which the Treasury met its obligations, carried out by the Equality and Human Rights Commission. ${ }^{92}$ In addition, subsequent budgetary and spending announcements, for example in March 2011, were accompanied by EIAs, albeit that these were deemed inadequate by campaigning groups. ${ }^{93}$

In sum, then, when self-regulation has failed and legal cases have been brought, using the judicial review procedure, we have not seen significant success in overturning decisions; ${ }^{94}$ and yet these cases have certainly had some impact. Case law has developed guidance regarding the steps that are expected of public authorities in complying with the duty; and the cases themselves have had some educative effect, with public authorities more sensitive to equality issues in their decision making.

\section{iiii. Power relations}

The third area of concern identified was that reflexive regulation is unable to address the conflicting political and economic interests in play when considering equality in the public sector. This limitation is particularly pertinent given that the PSED came into force at a time when the UK was still struggling with the aftermath of a global recession caused by a major financial crises, in response to which the UK government pursued an economic policy of austerity. The ability of the PSED to be effective against a background of austerity and public service cuts provides a good test of its capacity to address broader power struggles as well as to counter the neo-liberal economic turn. The evidence regarding the implementation of the PSED is that it has not stood up well to this challenge.

An example can be seen in the failure of the Fawcett Society's case challenging the first austerity budget in 2010. Although it may have had some impact, as discussed above, the Court did not grant permission to seek judicial review and the legal challenge failed. ${ }^{95} \mathrm{~A}$ second example illustrating the failure of the duty to challenge neo-liberal economic policies involves the increase in university tuition fees to $£ 9,000$, introduced by the UK Coalition government in 2010. Here the government complied with the duty, by undertaking an equality impact assessment of the policy. Its assessment concluded that the increase in tuition fees was likely to benefit female graduates and those from an

http://www.fawcettsociety.org.uk/wp-content/uploads/2013/02/The-Impact-of-Austerity-on-Women19th-March-2012.pdf (Accessed 7 July 2017); The changing labour market: delivering for women, delivering for growth (London: The Fawcett Society, 2013) available at http://www.fawcettsociety.org.uk/wp-content/uploads/2013/04/Fawcett-The-changing-labourmarket.pdf (accessed 7 July 2017); The Fawcett Society's Policy Submission to the Review of the Public Sector Equality Duty available at: http://www.fawcettsociety.org.uk/wpcontent/uploads/2013/04/Fawett-submission-to-Review-of-the-Public-Sector-Equality-Duty-April2013.pdf (accessed 7 July 2017).

${ }^{92}$ The Gender Impact of the Cuts - a year on (TUC, 2011) available at: https://www.tuc.org.uk/sites/default/files/tucfiles/genderimpactofcutsrevisited.pdf (accessed 7 July 2017).

${ }^{93}$ C. Annesley, 'Campaigning against the Cuts: Gender Equality Movements in Tough Times' (2012) 83

Political Quarterly 19.

${ }^{94}$ See further S. Fredman (2011) ibid at fn. 9.

${ }^{95}$ H. Conley (2012) ibid at fn. 64. 
ethnic minority background, since they were more likely to earn below the threshold of $£ 21,000 .{ }^{96}$ Although this is factually correct it shows that the duty can expose underlying structural issues which are at the root of inequality but it has no power to address them. This supports the concerns identified by Ashiagbor ${ }^{97}$ and Black ${ }^{98}$ that second-generation regulatory mechanisms can uphold policies that run counter to equality as long as the organisation has fulfilled its procedural requirements to have 'due regard' to the need to promote equality.

The theme of austerity can be found in the evidence provided by those who took part in roundtable discussions and focus groups run as part of the PSED review. Two conflicting perspectives emerge from the recorded responses. ${ }^{99}$ The first stresses that the PSED has the potential to safeguard some of the most disadvantaged groups from the impact of the cuts, by ensuring that customers' and employees' needs are understood, and that equality is embedded within public bodies. In contrast, the second view highlighted the importance of decision-makers showing that they had had 'due regard' and had considered equality issues so that their decisions about cutting services and reducing resources would be perceived as fair. In effect, if those likely to be affected by public authorities' decisions believe that their needs have been considered and that they have been listened to, even if the outcome of any decisions affects them negatively, they are more likely to accept them. ${ }^{100}$ According to this more cynical view, the application of the duty ensures that the decision-making process is seen as fair, with the perverse effect of legitimising cuts to services and resources for disadvantaged and more vulnerable groups. This accentuates Fredman's concern that the PSED may fail to redress inequalities in economic power, and may merely justify the re-distribution of poverty. ${ }^{101}$

These examples suggest that the concerns relating to the weakness of reflexive regulation to address conflicting political and economic interests are not misplaced. They suggest that while reflexive regulation may play an educative role, and may lead to some examples of good practice infiltrating the public and even the private sector, nonetheless, it is ineffective at a deeper level in addressing systemic inequality, and may even end up reinforcing neo-liberal economic policies, by providing a veneer of equality which hides the deepening inequality beneath.

\footnotetext{
${ }^{96} R$ (on the application of Hurley and Moore) $v$ Secretary of State for Business, Innovation and Skills [2012] EWHC 201 (Admin).

${ }^{97}$ D. Ashiagbor, 'Evaluating the Reflexive Turn in Labour Law' (2015) ibid., at fn. 39.

98 J. Black (2000) ibid., at fn. 5 at 598.

${ }^{99}$ Note of Roundtable Claimant Lawyers 26 March 2013; Review of the Public Sector Equality Duty (PSED) Note of Site Visit: A City Council (a): 7

https://www.gov.uk/government/uploads/system/uploads/attachment data/file/249362/Round table write ups.zip [accessed 6th October 2016].

${ }^{100}$ Note of Roundtable Claimant Lawyers 26 March

2013https://www.gov.uk/government/uploads/system/uploads/attachment data/file/249362/Round table write ups.zip [accessed 6th October 2016].

101 S. Fredman (2011) ibid., at fn. 9.
} 


\section{B. Re-assessing concerns regarding the PSED}

The examples discussed abovehave been chosen because they are illustrative of the types of response that can be found across different sectors, including employment and service delivery. They illustrate the equality outcomes that can be delivered through second-generation regulation, including examples of the duty infiltrating the private sector through the process of procurement and contracting out of services. Clearly very many more examples could be given of ways in which the duty has been implemented to the benefit of disadvantaged individuals and groups, and to that extent the PSED has clearly had a beneficial effect in changing, to an extent, how organisations operate.

However, in part two above, some serious concerns were raised regarding the use of second-generation regulatory mechanisms such as reflexive law to deliver equality. These were concerns related to process, such as the representativeness of any consultation; practical concerns regarding enforcement; and deeper concerns regarding the capacity for regulation to challenge or even to reinforce the neo-liberal turn in economic policies. If the effectiveness of the PSED is to be more fully assessed, these concerns need to be carefully considered, to determine whether they are borne out in the evidence.

Despite the systemic weakness of reflexive regulatory mechanisms in tackling underlying power relations, some areas of strength can be identified, suggesting that there are some respects in which it has been effective. This is particularly the case if the underlying aims of equality are taken into account. For example, despite the concerns regarding the representativeness of the consultations undertaken in compliance with the duty, nonetheless, the process of consultation itself does hold the potential to fulfil aspects of the equality aims of the duty.

The PSED is underpinned by a transformative model of equality, based on the idea of inclusion, with the aim of ending marginalisation and disadvantage and promoting social justice. The idea is that equality based on social inclusion can be achieved by encouraging minority or disadvantaged groups to participate in civic life, so that their voice within the community can become stronger. ${ }^{102}$ Once this inclusionary dimension to equality is understood, it becomes clear that a significant strength of the PSED is the way that it leads to consultation and involvement of relevant groups, thereby creating a series of interactions which can promote participation in public life and foster good relations between different groups. In effect, the very processes that the PSED encourages are equality outcomes in and of themselves.

Viewed through the lens of equality as inclusion and dignity, then, the processes introduced in order to comply with the PSED may be more valuable than is usually contended, and the concerns identified above about the process of consultation and about enforcement become a little less acute. This is because the process of consultation is of itself beneficial. The groups consulted gain in recognition and thus in dignity by

102 S. Fredman, (2002) ibid. at fn. 20; H. Collins ibid., at fn. 21. 
virtue of the consultation process. Indeed, to the extent that they encourage involvement and participation by the relevant groups, it may be that the bureaucratic processes themselves should be understood as helping to fulfil the aims of the PSED. This does not, of course, take away from the need to ensure that the correct groups are consulted and it is not suggested that concerns regarding consultation should be disregarded. Nonetheless, if equality is understood less as to do with formal equality and same treatment, and more as a notion involving inclusion and participation in public life, then the very process of consultation with disadvantaged groups achieves these aims. Rather than being written off as so much red tape, then, the existence of these potentially bureaucratic 'tick box' processes can be understood in part as successful equality outcomes, as the process itself brings benefits of inclusion and participation to those consulted. Of course, additional benefits are to be welcomed where they result, but on this view, even the bureaucratic approaches that were a focus of concern regarding the implementation of the duty, can be understood as achieving equality in terms of inclusion.

The second set of concerns related to weaknesses in enforcement, due to the reliance on judicial review rather than individual complaints. Although these concerns remain valid, they are in part met through recognising the educative effect of the cases that have been brought, as public organisations seek to avoid litigation by 'equality proofing' their decision making processes. Moreover, the fact that additional regulatory measures have been introduced within particular sectors, such as the Care Quality Commission equality standards, 103 mean that further avenues of enforcement have developed beyond either individual complaints-led models or judicial review.

The third concern related to the ability of the regulatory mechanism used by the PSED to address deeper systemic issues regarding power relations in public bodies. In this regard, the PSED has admittedly had limited success. This is illustrated particularly clearly in the context of the ability of the PSED to be used to counter austerity measures, which have been shown to have had unequal impacts on different equality groups, with women being particularly disadvantaged. Indeed it could be argued that the equality proofing of policies that the PSED encourages may provide a veneer of acceptability to policies which in practice lead to deeply unequal results, not merely failing to address underlying inequality, but actually reinforcing it.

Despite this systemic weakness of reflexive regulatory mechanisms in tackling underlying power relations, some benefits of a reflexive regulatory approach can nonetheless still be identified in comparison to complaints-led direct enforcement processes. Directly enforceable individual rights are usually seen as strong safeguards for the interests they protect. However, they can also be vulnerable, because rights that are given can also be taken away, directly, or indirectly, as has been seen recently with

\footnotetext{
103 See Care Quality Commission equality standards at www.cqc.org.uk/content/equality-and-humanrights (accessed 15 July 16).
} 
the introduction of tribunal fees. ${ }^{104}$ Moreover, the continued contracting out of public services can lead to the undermining of public sector standards.

Thus individual complaints-led enforcement of equality norms can also prove fragile. In contrast, where internal organisational processes have been changed, and where additional external regulatory measures have been introduced such as the Athena Swan charter in the higher education sector, these changes may in the event be seen to be more robust. To return to the biological metaphor underpinning systems theory, the introduction of external regulatory mechanisms such as the equality requirements of Athena Swan and the Care Quality Commission mean that the receiving organisations are 'infected' by equality processes, and these processes can be hard to 'disinfect'. Thus although the PSED may be viewed as weak due to its failure to address underlying inequalities, nonetheless, the indirect implementation processes espoused by the PSED do have some residual strength, as they have the capacity to withstand the dismantling of more formal enforcement mechanisms by the state, as well as the removal of a range of services from state provision.

Assessed in the light of its equality aims, then, the PSED can be seen to have some strengths, despite its underlying weaknesses. In particular, using second-generation regulatory mechanisms to implement the duty seems to be the main means by which it has achieved the success it has had. In the final section, some suggestions are made regarding how best to develop the regulatory mechanisms used by the PSED to try to maximise their ability to meet their objectives of enhancing equality and social justice.

\section{Improving effectiveness of reflexive regulation to achieve equality outcomes}

The examples of the practical implementation of the PSED explored above point to four procedural aspects which will need to be working as well as possible if secondgeneration regulation is to be most effective: data collection; consultation; capacity building and leadership; and enforcement or sanctions. These can loosely be mapped onto of Hepple's three interlocking regulatory mechanisms; data collection being the first mechanism, allowing for internal scrutiny by the organisation; consulting and engaging with interest groups being the second; and the third, enforcement. 105

\section{A. Data collection}

As seen earlier, data collection and analysis is of key importance in enabling organisations to self-regulate. Many organisations collect and analyse relevant data and undertake monitoring to provide a strong evidence base for internal organisational scrutiny. Indeed, standardised data collection is required across the public sector on a

\footnotetext{
${ }^{104}$ Employment claims reduced dramatically since the introduction of the significantly increased fees in 2013. https://www.gov.uk/government/statistics/tribunal-and-gender-recognition-statistics-quarterlyoctober-to-december-2015, accessed 7 April 2016.

105 B. Hepple (2011) ibid., at fn 22.
} 
range of indicators. For example HESA data is collected in higher education, ${ }^{106}$ and police forces are required to provide data to the Home Office on a wide range of issues including use of stop and search powers by different racial groups.

The collection of data allows organisations to identify areas where self-regulation is needed and to assess the effectiveness of its application and outcomes. Data collection and analysis, along with monitoring also support transparency and accountability as well as providing a basis for improving policies and decisions. Effective implementation of the PSED is clearly reliant on effective monitoring, through which the challenges facing protected groups in terms of equality can be identified. Where the quality of the data is reduced, the equality outcomes are likely to be reduced in tandem.

Yet some broad risks to the quality of the data can be identified. First is that, particularly given the reduction in the requirements of the specific duties in England, and exacerbated by funding cuts, there will be a reduced commitment to collecting and analysing data beyond any externally imposed sectoral requirements. With reduced data regarding equality it will be harder to create tailored responses to address the particular needs of vulnerable groups in a particular workplace. A second, related risk is that even though data is requested, respondents can be reluctant to disclose what they regard as personal and sensitive information, so that data becomes an unreliable basis for action. It is therefore necessary to continue to build trust that the provision of equality related information when applying for a job, or when using a public service, is for the purposes of promoting equality, rather than for any suspect purpose, so that any policy responses to inequality are based on reliable information.

A third difficulty with regard to the collection of data for equality purposes is that most data requested is based on single characteristics. The categories for race and ethnicity are often based on census categories. The use of such categories clearly helps with data analysis, allowing any changes to be tracked over time, but the categories can themselves be contested. The continued use of such categorisations in the context of the PSED will carry forward any concerns about their validity into its implementation.

Moreover, understandings of equality have developed beyond notions based on single characteristics, to recognise the importance of intersectionality and multiple discrimination. ${ }^{107}$ The data collected by most organisations is based on single characteristics, and identifying from the data any intersectional issues is likely to be difficult. This can mean that the ability of reflexive law mechanisms to address intersectional issues of equality is likely to be limited, particularly where the data is collected in small samples in small organisations.

\footnotetext{
106 Higher and Further Education Act 1992.

107 I. Solanke 'Infusing the Silos in the Equality Act 2010 with Synergy' (2011) 40 Industrial Law Journal 336.
} 


\section{B. Depth and reach of consultation}

As well as gathering and analysing good data, there is a need for proper engagement and consultation with relevant stakeholders if Hepple's second mechanism, selfscrutiny, is to be effective. The involvement of interest groups is well evidenced in the many examples of consultation with service users and the involvement of equalities groups in forming expert panels and becoming involved in decision-making. ${ }^{108}$ Although the strong potential for the process of consultation to achieve equality was recognised above, consultation needs to reach the right participants, and ensure truly engaged participation. Otherwise a small range of well consulted representatives may benefit, but the voices of more marginal members of minority groups are likely to be lost, and those groups will lose out on the equality benefits of participation and inclusion.

In order to address the problem of 'consultation fatigue', identified above, it is important to ensure a spread of participants, and to ensure that those consulted can see that they have some influence on the actual decision making process. Any consultation will need to engage participants, rather than merely 'involving' them in the consultation process. Instead, a 'thick' or deep conception of the consultation process is needed,109 one that allows all opinions to be voiced in conditions of equality, and for decision making to be conditioned by the desire to reach agreement.

The experience of implementing the PSED in practice, reported above, suggests that if it is to effect change, reflexive regulation needs to lead to processes that are fully participative and deliberative, in terms of both the reach and depth of the consultation that takes place.

\section{Leadership and capacity building}

The experiences of the implementation of the PSED reported above, suggests that visible, committed and coordinated leadership is essential if the duty is to be effective. Moreover, equalities expertise within institutions (such as 'champions' or dedicated staff with a specific equalities remit) can play a significant role in ensuring the effectiveness of any internal scrutiny as well as 'sensitising' the environment, making it more receptive to equality concerns. Equally, a commitment to training is important to build capacity and is key to the success of equalities initiatives at all levels.

Clearly not all organisations will have the resources to fund such expertise: it would not be cost efficient for every primary school, GP surgery or small service contractor to employ a dedicated equalities expert. However, dedicated expertise to provide advice, guidance and training on good practice further up the 'command chain' is vital if indirect forms of regulation are to be effective. Such expertise clearly already exists and

\footnotetext{
108 See for example, Disability Charities (2013) ibid., at fn. 79.

109 J. Black (2000) ibid., at fn. 5 at 598.
} 
many examples of good practice can be found; to take the higher education context as an example, Vitae ${ }^{110}$ produces resources such as they 'Every Researcher Counts' programme, to support equality and diversity in researcher careers, and the Equality Challenge Unit ${ }^{111}$ produces guidance to help embed equality and diversity into student recruitment, retention and attainment as well as within human resources systems.

As well as developing good practice and making examples easily available, leadership is also necessary if equality outcomes are to be achieved through indirect regulatory methods. In larger organisations, that leadership needs to come from senior management level in order to signal its importance.

\section{Enforcement or sanctions}

There is no doubt that the regulatory mechanism of reflexive law only works if backed by effective enforcement, even if only to be used as a last resort. ${ }^{112}$ And yet, the judicial review process is fragile, and the EHRC has been weakened by under-funding. There is arguably therefore little incentive to comply with the duty, meaning that organisations may downgrade their processes for compliance with the duty. In order for secondgeneration regulation to be effective, then, it remains imperative for adequate enforcement mechanisms to be available when traditional regulation fails. Formal enforcement may not be used very often, but the potential for its use is necessary for the more indirect forms of regulation to operate effectively. As has been seen, secondgeneration regulation can be both efficient and effective as an engine of change but only when in the presence of a realistic background enforcement mechanism. Judicial review and its 'due regard' standard, identified as inadequate by Fredman and others, therefore remains a serious weakness. Reflexive regulation cannot be expected to be fully effective if it is not ultimately backed by realistic prospects of legal action.

\section{Conclusion}

Using the PSED as an example of second-generation regulation, a number of lessons can be learnt. The approach to legal regulation based on indirect mechanisms and systems change has been subject to some significant concern, not least its inability to address structural questions of power relations and embedded inequality. In particular, the PSED does not seem to have been able to withstand the process of austerity cuts, many of which have a direct and detrimental impact on equality and social justice. Not only have challenges to the cuts themselves been largely ineffective, but also those working in equality either for the EHRC or within organisations have faced job cuts as austerity has reduced staffing levels in what have been seen as non-frontline jobs.

\footnotetext{
${ }^{110}$ www.vitae.ac.uk/ (accessed 7 July 2017).

${ }^{111}$ www.ecu.ac.uk/ (accessed 7 July 2017).

112 S. Deakin and C. McLaughlin (2007) ibid at fn 30. See also B. Hepple (2011) ibid at fn 22, citing J

Braithwaite, Restorative Justice and Responsive Regulation (Oxford: OUP, 2002).
} 
These weaknesses could call into question the use of second-generation regulation as a mechanism for achieving equality. Yet, it is our contention that that this method of regulation has, nonetheless, some particular strengths as a mechanism for achieving equality outcomes.

Despite the undoubted weakness of the duty in addressing power structures, the way in which equality has nonetheless 'infected' a number of other regulatory mechanisms demonstrates a resilience in the self-regulation system that is encouraged by secondgeneration regulation. 'Infection' can be seen in the way in which organisations have set up their own processes to enable them to comply with the duty, as well as in the various external regulators such as the Care Quality Commission and voluntary initiatives such as the Athena Swan Charter and Investors in People. These initiatives are now well established in their own right and have normalised and embedded equality standards into management good practice.

Moreover, the fact that the PSED can be shown to have 'infected' other systems means that it is not so easy to undo or unpick those systems, even if there is no direct means of enforcement. Instead, the infiltration of equality concerns into procurement processes, and other external audit processes may take some time to undo, even if the underpinning enforcement mechanisms are absent or weak. This is certainly not to say that the absence of formal enforcement does not matter: clearly it does. A realistic threat of legal enforcement is vital. But, nonetheless, the ability of the 'infection' to survive in the absence of strong enforcement, does show that this form of regulation has a degree of resilience in the face of adverse power relations.

An additional strength of second-generation regulation can be seen in its complementary relationship with more traditional complaints-led regulation. Equality legislation has already sensitised some areas such as employment and service delivery to equality issues: the addition of the PSED has helped develop cultural change by embedding equality standards deeper into organisational practices.

The final way in which second-generation regulation can be effective, has special application in the context of equality. This is the recognition that the consultation processes, set up as part of the reflexive regulatory process, are themselves means by which some aspects of equality are achieved. Equality as used in the provisions of the PSED includes tackling prejudice, fostering good relations and eliminating discrimination and disadvantage; it also aims to increase participation and inclusion, thereby reducing marginalisation of vulnerable groups. This is achieved by allowing those experiencing inequality to be directly involved in the decision making processes of those whose decisions affect them. As a result, second-generation regulation, with its participatory methods of enforcement, is particularly suited as a regulatory mechanism to enhance equality, because the processes that are set up in accordance with the PSED are, in themselves, a means of achieving this transformative form of equality. 
This is certainly not to suggest that the processes of the PSED cannot be improved, and a number of ways in which second-generation regulation can be made more effective with respect to equality have been identified. Processes of consultation need to have both reach and depth: they need to be made as participatory as possible, with a focus on deliberation and openness to reach conclusions that the majority are happy with. In addition, effective second-generation regulation requires effective leadership on equality issues within organisations, with the process being most effective if selfregulation is led from senior management. Where this occurs, the example of the PSED shows that reflexive regulation can, despite its inherent fragility, provide more effective and resilient means to support the realisation of equality and social justice than at first appears. 